\title{
Chemical Composition and Hypotensive Effect of Campomanesia xanthocarpa
}

\section{Liane Santariano Sant'Anna, ${ }^{1}$ Liara Merlugo,, Catrine Santos Ehle, ${ }^{1}$ Jessica Limberger, Maquelen Blanco Fernandes, ${ }^{1}$ Marí Castro Santos, ${ }^{1}$ Andreas Sebastian Loureiro Mendez, ${ }^{2}$ Fávero Reisdorfer Paula, ${ }^{1}$ and Cleci Menezes Moreira ${ }^{1}$}

${ }^{1}$ Universidade Federal do Pampa, Uruguaiana, RS, Brazil

${ }^{2}$ Faculdade de Farmácia, Universidade Federal do Rio Grande do Sul, Porto Alegre, RS, Brazil

Correspondence should be addressed to Cleci Menezes Moreira; clecim2@gmail.com

Received 23 February 2017; Revised 12 April 2017; Accepted 26 April 2017; Published 11 May 2017

Academic Editor: Orazio Taglialatela-Scafati

Copyright (C) 2017 Liane Santariano Sant'Anna et al. This is an open access article distributed under the Creative Commons Attribution License, which permits unrestricted use, distribution, and reproduction in any medium, provided the original work is properly cited.

\begin{abstract}
Campomanesia xanthocarpa is known in Brazil as Guabiroba and is popularly used for various diseases, such as inflammatory, renal, and digestive diseases and dyslipidemia. The aim of the study was to analyze the chemical composition and investigate the effects of aqueous extract of C. xanthocarpa on the blood pressure of normotensive rats, analyzing the possible action mechanism using experimental and in silico procedures. The extract was evaluated for total phenolic compounds and total flavonoid content. The chemical components were determined by HPLC analyses. Systolic and diastolic blood pressure and heart rate were measured with extract and drugs administration. The leaves of C. xanthocarpa presented the relevant content of phenolics and flavonoids, and we suggested the presence of chlorogenic acid, gallic acid, quercetin, and theobromine. The acute administration of aqueous extract of $C$. xanthocarpa has a dose-dependent hypotensive effect in normotensive rats, suggesting that the action mechanism may be mediated through the renin-angiotensin system by AT1 receptor blockade and sympathetic autonomic response. Docking studies showed models that indicated an interaction between chlorogenic acid and quercetin with the AT1 receptor (AT1R) active site. The findings of these docking studies suggest the potential of C. xanthocarpa constituents for use as preventive agents for blood pressure.
\end{abstract}

\section{Introduction}

Essential hypertension is a highly prevalent pathological condition that is considered one of the most relevant cardiovascular risk factors and is an important cause of morbidity and mortality around the world. Major effects on renal and cardiovascular physiology attributed to angiotensin II are mediated through the ATIR [1]. Chronic activation of the AT1R can lead to disease states, including hypertension, cardiac arrhythmia, stroke, diabetic nephropathy, and metabolic disorders [2-4]. The ATla receptor is well expressed in most cardiovascular tissues and is the principal regulator of blood pressure [5], which is effectively treated using AT1R blockers $[4,6,7]$
Many synthetic drugs have been widely used for the treatment of hypertension, but herbal medicines still remain a popular choice. The abundant use of these medicinal plants has led to extensive research in this area to determine their potential efficacy, and modern cardiovascular drugs are now available as natural products [8].

In Brazil, Campomanesia xanthocarpa (Myrtaceae), popularly known as "Guabiroba," possesses a wide spectrum of physiological effects. The leaves of this plant are used as an infusion in folk medicine to treat inflammatory, urinary, and rheumatic diseases, and hypercholesterolemia [9]. Moreover, it is empirically used for weight loss and for the control of many conditions associated with obesity [10]. Scientific studies demonstrate that C. xanthocarpa extract 
presents mutagenic potential, synergistic effects that result in comutagenic activity [11], has antiproliferative and genotoxic activities using the in vivo Allium cepa root-tip cell test and an increase in the frequency of chromosome aberrations [12], has antiplatelet, antithrombotic, and fibrinolytic activities, may be effective in preventing thrombus formation through several pathways [13], reducing blood cholesterol levels [14], has a gastroprotective effect [15], and reduces oxidative stress and inflammatory processes $[16,17]$; it may therefore have therapeutic applications.

Natural biological active compounds in plants have a significant role in vegetable defense mechanism and are also important for their unambiguous physiological actions in human body. Due to their therapeutic properties, secondary metabolites (flavonoids, alkaloids, tannins, saponins, and terpenoids) are becoming a part of the integrative health care system as supportive and alternative medicines [18]. Thus, knowing the chemical composition of these medicinal plants is very important.

Phytochemical analysis from the leaves of C. xanthocarpa extract indicated the presence of flavonoids, saponins, tannins, and terpenes [12, 14, 15]; these compounds have known biological potential. Thus, the objective of this study is to investigate the chemical composition of C. xanthocarpa extract, evaluate the hemodynamic parameters, and investigate the action mechanism of the aqueous extract in rats by experimental and in silico procedures (docking analysis).

\section{Material and Methods}

2.1. Plant Material. Campomanesia xanthocarpa was collected in July 2014 in Uruguaiana/RS (Brazil). The materials were identified, and a voucher specimen was deposited at the Herbarium of Universidade Federal do Pampa-São Gabriel/RS.

2.2. Extract Preparation. The leaves were selected, dried at a temperature of $40^{\circ} \mathrm{C}$, ground, and submitted to an infusion using distilled water at a temperature of $100^{\circ} \mathrm{C}(1: 10$, plant: solvent), used in chromatographic assays.

For biological analysis, the infusions were oven-dried, reduced to powder, and rediluted in $0.9 \%$ saline solution for administration.

\subsection{Characterization of Plants and Extracts}

2.3.1. Total Phenolic Content. The Folin-Ciocalteu colorimetric method with some modifications was used to determine the total phenolic content [19]. To a test tube were added $100 \mu \mathrm{L}$ of the sample, $500 \mu \mathrm{L}$ of Folin-Ciocalteu, and $6 \mathrm{~mL}$ of water; the tube was agitated and left to rest for one minute. Two milliliters of $\mathrm{Na}_{2} \mathrm{CO}_{3}$ solution $15 \%$ was added after alkalizing the medium, and the volume was completed to $10 \mathrm{~mL}$ with distilled water. It was read in a spectrophotometer Perkin Elmer UV-VIS Lambda $35^{\circledR}$ (Norwalk, CT, USA) at a wavelength of $750 \mathrm{~nm}$ after 30 minutes at room temperature and protected from light. The total phenolic content was expressed in milligrams of gallic acid equivalent per $\mathrm{mL}$ of sample (mgGAE/mL).
2.3.2. Total Flavonoid Content. The method described by Chang et al. [19] was used with some modifications to determine the total flavonoid content. To a $25 \mathrm{~mL}$ flask were added $500 \mu \mathrm{L}$ of the sample and $500 \mu \mathrm{L}$ of $\mathrm{AlCl}_{3} 0.5 \%$, and the volume was completed with water. The reading was done in a Lambda 35 Perkin Elmer UV-VIS spectrophotometer (Norwalk, CT, USA) at a wavelength of $415 \mathrm{~nm}$ after being incubated for 40 minutes at room temperature and protected from light. The results were expressed in rutin mg equivalents/g (mgRE/g).

2.4. HPLC-DAD Assay. Chromatographic analyses were performed using a Prominence Shimadzu ${ }^{\circledR}$ HPLC system (Kyoto, Japan) equipped with an LC-20AT pump, SIL-20A autoinjector, SPD-20AT detector, CTO-20A column oven, and LC Solution V. 1:24 SP1 software. The chromatographic separation was performed in a RP-C18 column Hypersil C18 Thermo-Scientific $(250 \times 4.0 \mathrm{~mm}, 5 \mu \mathrm{m})$ using a mobile phase of $5 \%(\mathrm{v} / \mathrm{v})$ acetonitrile (solvent $\mathrm{A})$ or $50 \%(\mathrm{v} / \mathrm{v})$ acetonitrile (solvent B) containing $0.05 \%(\mathrm{v} / \mathrm{v})$ phosphoric acid (85\%), with a $1 \mathrm{~mL} / \mathrm{min}$ flow rate, Diode Array Detector (DAD) at $280 \mathrm{~nm}$ and $340 \mathrm{~nm}$, and an injection volume of $40 \mu \mathrm{L}$. The gradient was programmed as follows: solvent A was maintained at 90\%, and solvent B was maintained at $10 \%$ within the first 14 minutes. B increased linearly from $10 \%$ to $15 \%$ over 14-20 minutes, and this condition was maintained for four minutes. B increased linearly from $15 \%$ to $70 \%$ over 24-40 minutes and this condition was maintained for four minutes. The chromatographic parameters were adapted from Yang et al. [20] method.

To identify and suggest the presence of components in the leaf extract of $C$. xanthocarpa, peak retention times were studied and a thorough comparison between sample and standard references was made. The standard compounds used were gallic acid $(200 \mu \mathrm{g} / \mathrm{mL})$, chlorogenic acid $(200 \mu \mathrm{g} / \mathrm{mL})$, quercetin $(200 \mu \mathrm{g} / \mathrm{mL})$, luteolin $(100 \mu \mathrm{g} / \mathrm{mL})$, isoquercetin $(100 \mu \mathrm{g} / \mathrm{mL})$, quercitrin $(100 \mu \mathrm{g} / \mathrm{mL})$, theobromine $(35 \mu \mathrm{g} / \mathrm{mL})$, caffeic acid $(35 \mu \mathrm{g} / \mathrm{mL})$, and caffeine $(35 \mu \mathrm{g} / \mathrm{mL})$, prepared with ethanol 50\% (v/v). Extract samples and references standards were analyzed in triplicate.

\subsection{Evaluation of Blood Pressure and Possible Action Mechanisms of the Campomanesia xanthocarpa Extract}

2.5.1. Animals. Male Wistar rats were used that were three months old and purchased from Universidade Federal de Santa Maria. They were kept in cages with a controlled temperature $\left(22^{\circ} \mathrm{C}\right), 12$ hour dark/light cycle, food, and water ad libitum.

The experimental protocols followed the International Principles for Research Involving Animals (Geneva), Brazilian legislation by Law No. 11.794/2008 (Procedures for the Scientific Use of Animals), and Decree 24.645/34 (animal rights) and were approved by the Ethics Committee on Animal Use (ECAU) of the university (Protocol 017/2014).

After all of the protocols, the animals were sacrificed using the guillotine while still under the effects of the anesthesia. 
2.5.2. Hemodynamic Parameters. The rats were submitted to surgery for catheterization of the carotid artery (to measure the hemodynamic parameters) and the jugular vein (for extract and drugs administration), with polyethylene catheters (PE10 Clay-Adams) filled with heparinized saline $(50 \mathrm{IU} / \mathrm{mL})$, under anesthesia with urethane $(1.4 \mathrm{~g} / \mathrm{kg}$, i.p.), which was assessed by responsiveness to painful stimuli and supplemented when necessary [21]. The arterial catheter was connected to a pressure transducer coupled to an analog digital converter (Biopac Systems MP150, Inc.; CA).

2.5.3. Extract Curve. For evaluation of the extract effects on hemodynamic parameters, a rising curve was done, after 30 minutes of stabilization. A total of $25,50,75,100,125,150$, 175 , and $200 \mathrm{mg} / \mathrm{kg}$ of extract cumulative were administered, with a volume of $0.2 \mathrm{~mL}$ of saline; each dose was administered 15 minutes after the other $(n=8)$. Systolic blood pressure (SBP), diastolic blood pressure (DBP), and heart rate (HR) were recorded over approximately 3 hours.

2.5.4. Evaluation of Possible Action Mechanisms of the Extract. For the investigation of mechanisms involved in the extract hypotensive action, certain drugs were tested after $30 \mathrm{~min}-$ utes of stabilization: $\mathrm{N}_{\omega}$-nitro-L-arginine methyl ester (LNAME), an nitric oxide (NO) synthesis inhibitor $(30 \mathrm{mg} / \mathrm{kg}$, $n=6)$; losartan, AT1 receptor antagonist of angiotensin II (10 mg/kg, $n=6)$; and hexamethonium, a ganglionic blocker (20 mg/kg, $n=6$ ) [21-23]. After drug administration, a new stabilization period was conducted, and then the extract (5 to $100 \mathrm{mg} / \mathrm{kg}$ ) was administered, with the exception of the L-NAME protocol that used doses of 5 to $25 \mathrm{mg} / \mathrm{kg}$ because $50 \mathrm{mg} / \mathrm{kg}$ of the extract after administration of this drug caused a sharp decrease in blood pressure, inducing some animals' death. Hemodynamic records of SBP, DBP, and HR were taken.

2.5.5. Drugs. All drugs and reagents used were purchased from Sigma Chemical Co. (St. Louis, MO, United States).

2.6. Molecular Modeling Studies. Computational studies were performed with chlorogenic acid and quercetin, components determined in aqueous extract, to obtain information which aided in the understanding of the biological activity. Density functional theory (DFT) B3LYP/6-311G* , based in gas phase methodology, evaluable in Spartan'08 for Windows software (Wavefunction Inc., Irvine, United States) was used for geometry optimization and conformational analysis. The geometry of compounds was optimized followed by submission to systematic conformational analysis with a torsion angle increment set of $30^{\circ}$ in the range of $0-360^{\circ}$. The lowest energy conformer for chemical structure was saved in a $\mathrm{mol}^{2}$ file before use in the docking studies.

The structure of angiotensin II type 1 receptor, AT1R encoded PDB ID: 4YAY [24], was downloaded from the protein data bank (PDB) before performing the docking studies, and this $3 \mathrm{D}$ structure was prepared by removing the water molecules and adding polar hydrogens using Autodock Tools 1.5.6 [25]. Using iGemdock software [26], docking studies were performed in which the individual binding site of chlorogenic acid and quercetin were assessed and submitted to docking in the active site of the AT1R. Docking calculations were performed at drug screening docking accuracy setting with GA parameters set for population size, generation, and number of solutions as 200, 70, and 3, respectively, with a Gemdock score function of hydrophobic and electrostatic (1:1 preference). iGemdock software was used to infer the pharmacological interactions between the biological receptors and compounds studied.

2.7. Statistical Analysis. Data were expressed as the mean \pm standard deviation (SD), values were analyzed by one-way ANOVA for repeated measures and Tukey's post hoc, and $p<0.05$ was considered significant.

\section{Results}

3.1. Characterization of Plant and Extracts. The value of the total phenolic compounds found in the analysis of C. xanthocarpa extract was $3.7360 \mathrm{mgGAE} / \mathrm{mL}$ (relative standard deviation $2.87 \%$ ), and the flavonoid content was $2.5070 \mathrm{mgRE} / \mathrm{g}$ (relative standard deviation 3.45\%).

3.2. HPLC-DAD Analysis. The results showed the presence of many compounds in the crude extract of C. xanthocarpa. In Figure 1, it is possible to observe the complexity of plant matrix, whose constituents are being detected along the chromatographic run; in this case, the detection at $340 \mathrm{~nm}$ was focused in phenolic compounds. Compared to the reference standards, the similarity between retention times, besides UV spectra for chromatographic peaks, is indicative for the presence of gallic acid (compound 1), chlorogenic acid (compound 2), and quercetin (compound 3). In another assay (Figure 2), aiming to evaluate the xanthine derivatives and caffeic acid by performing the detection at $280 \mathrm{~nm}$, we suggest the presence of theobromine (compound 8) in the medicinal plant studied. It is important to mention that the peaks were evaluated using UV-DAD detection, whose UV profile data were thoroughly studied in order to confirm the chemical composition suggested (Figure 3).

\subsection{Evaluation of Blood Pressure and Possible Action Mechanisms of C. xanthocarpa Extract}

3.3.1. Evaluation of Hemodynamic Parameters in the Dosage Curve of C. xanthocarpa Extract. In the dose-administration curve, it can be observed that blood pressure decreased with the extract from $50 \mathrm{mg} / \mathrm{kg}$ in a dose-dependent manner. SBP and DBP decreased from $126.71 \pm 9.26$ to $68.14 \pm 9.99 \mathrm{mmHg}$ and from $81.85 \pm 12.58$ to $32.14 \pm 14.89 \mathrm{mmHg}$, respectively (Figure 4(a)). Heart rate also decreased in the presence of the extract from $50 \mathrm{mg} / \mathrm{kg}$ to $200 \mathrm{mg} / \mathrm{kg}$ (Figure 4(b)).

3.3.2. Evaluation of the Possible Action Mechanism of $C$. xanthocarpa Extract. As expected, L-NAME (Figure 5(a)) caused a hypertensive peak of $73.2-59 \mathrm{mmHg}$ (SBP-DBP), but when the extract was administered the blood pressure 
TABLE 1: Central pharmacological interactions (Van der Waals, H-bond, and electrostatic) of compounds and residues involved in the binding site of ACE-I with normal and applying the residues consensus analysis.

\begin{tabular}{|c|c|c|c|c|c|c|c|c|}
\hline Compounds & TYR 35 & TRP 84 & THR 88 & SER 105 & VAL 108 & SER 109 & ARG $^{*} 167$ & ILE 288 \\
\hline \multicolumn{9}{|l|}{ Chlorogenic acid } \\
\hline Van der Waals & -5.5 & -13.0 & 0.0 & -5.7 & -7.2 & 0.0 & -6.3 & -6.9 \\
\hline H-Bond & 0.0 & 0.0 & -2.5 & 0.0 & 0.0 & -4.2 & -4.1 & 0.0 \\
\hline Electrostatic & 0.0 & 0.0 & 0.0 & 0.0 & 0.0 & 0.0 & -1.9 & 0.0 \\
\hline \multicolumn{9}{|l|}{ Quercetin } \\
\hline Van der Waals & -4.2 & -19.0 & 0.0 & -6.9 & -0.2 & -5.1 & 0.0 & -8.2 \\
\hline H-Bond & -5.0 & 0.0 & 0.0 & -2.1 & 0.0 & 0.0 & -15.7 & 0.0 \\
\hline Electrostatic & 0.0 & 0.0 & 0.0 & 0.0 & 0.0 & 0.0 & 0.0 & 0.0 \\
\hline
\end{tabular}

${ }^{*}$ Confirmed by residue consensus analysis.

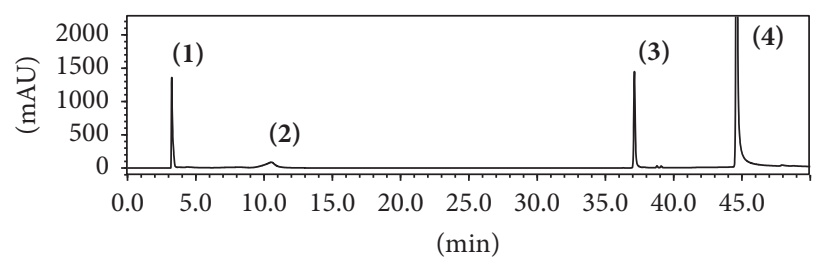

(a)

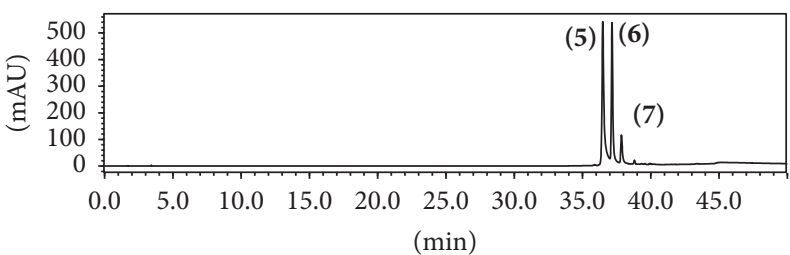

(b)

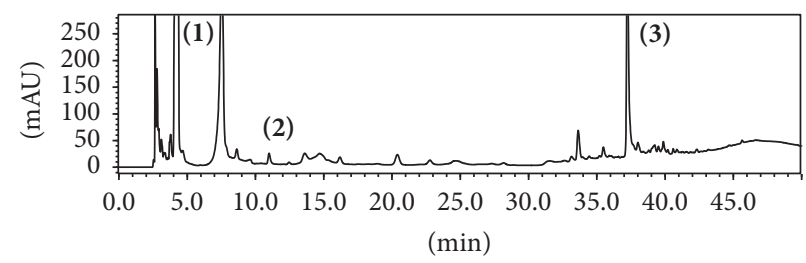

(c)

FIGURE 1: Representative chromatogram obtained in the analysis by HPLC-DAD wherein (a) phenolic standards are (1) gallic acid, (2) chlorogenic acid, (3) quercetin, and (4) luteolin; (b) phenolic standards are (5) vitexin, (6) isoquercetin, and (7) quercitrin; and (c) C. xanthocarpa aqueous extract, detection at $340 \mathrm{~nm}$.

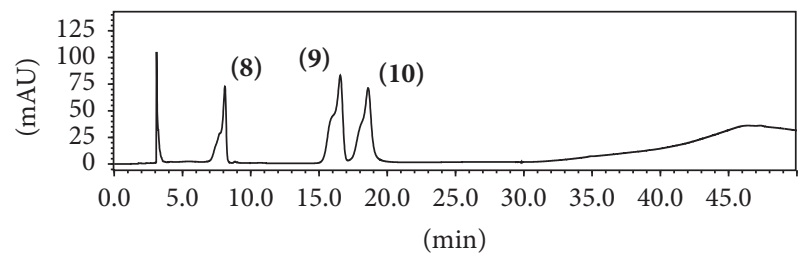

(a)

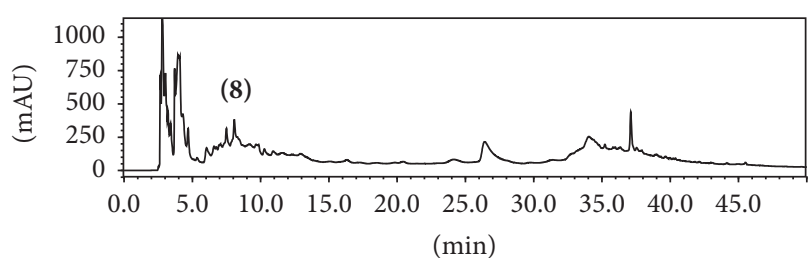

(b)

FIGURE 2: Representative chromatogram obtained in the analysis by HPLC-DAD wherein (a) xanthine standards and caffeic acid are (8) theobromine, (9) caffeic acid, and (10) caffeine and (b) C. xanthocarpa aqueous extract, detection at $280 \mathrm{~nm}$.

decreased to normal levels, suggesting that NO synthase mechanism is not involved in the hypotensive effect of the extract. The heart rate decreased in the presence of L-NAME after administration of the extract at doses of 20 and $25 \mathrm{mg} / \mathrm{kg}$ (Figure 5(b)).

Losartan (Figure 5(c)) and hexamethonium (Figure 5(e)) decreased blood pressure from $121.4 \pm 7.56 \times 84.2 \pm 12.87$ to $91.2 \pm 11.23 \times 49.4 \pm 5.27 \mathrm{mmHg}$ and $118.75 \pm 7.41 \times 74 \pm$ 4.76 to $101.75 \pm 7.18 \times 50.25 \pm 10.53 \mathrm{mmHg}$, respectively. After administration of these drugs, extract administration occurred, and no alterations to blood pressure were detected; this may mean that the hypotensive action of the extract can be implicated in the AT1R mechanism and sympathetic ganglionic blockade. In the losartan protocol, with $10 \mathrm{mg} / \mathrm{kg}$ of the extract, the heart rate decreased from $339 \pm 28.41$ to $274.4 \pm 30.16$ (Figure 5(d)). With hexamethonium, the heart rate was not altered (Figure 5(f)).

3.4. Molecular Modeling Studies. Molecular modeling studies were performed on two of the main components of aqueous extract from C. xanthocarpa: chlorogenic acid and quercetin (Figure 6). Docking was run using the conformer of minimal energy of chemical structure generated by Spartan, and results from the interaction are shown in Table 1 . The active 

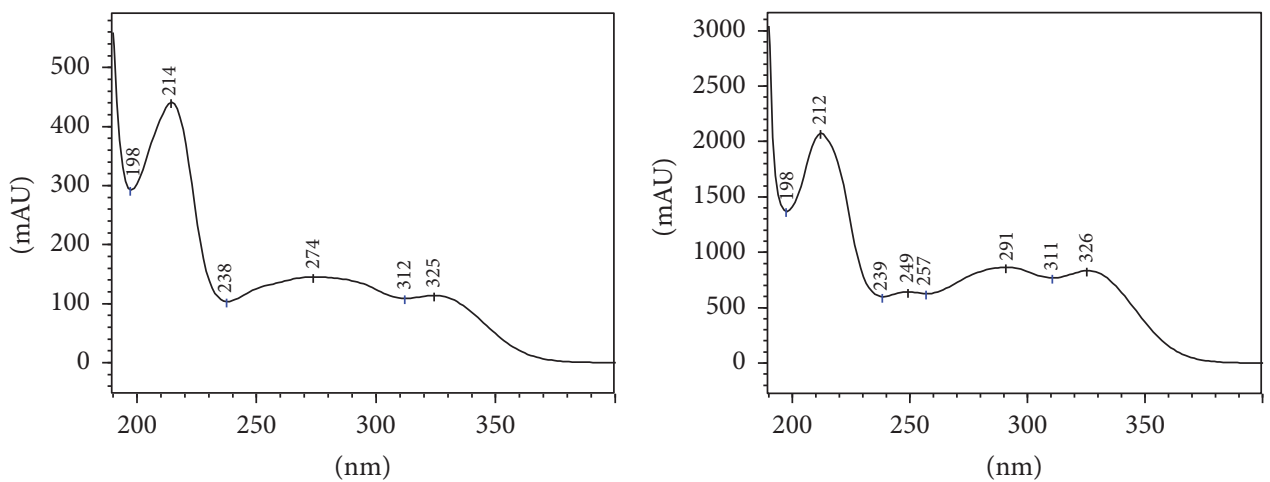

(a)
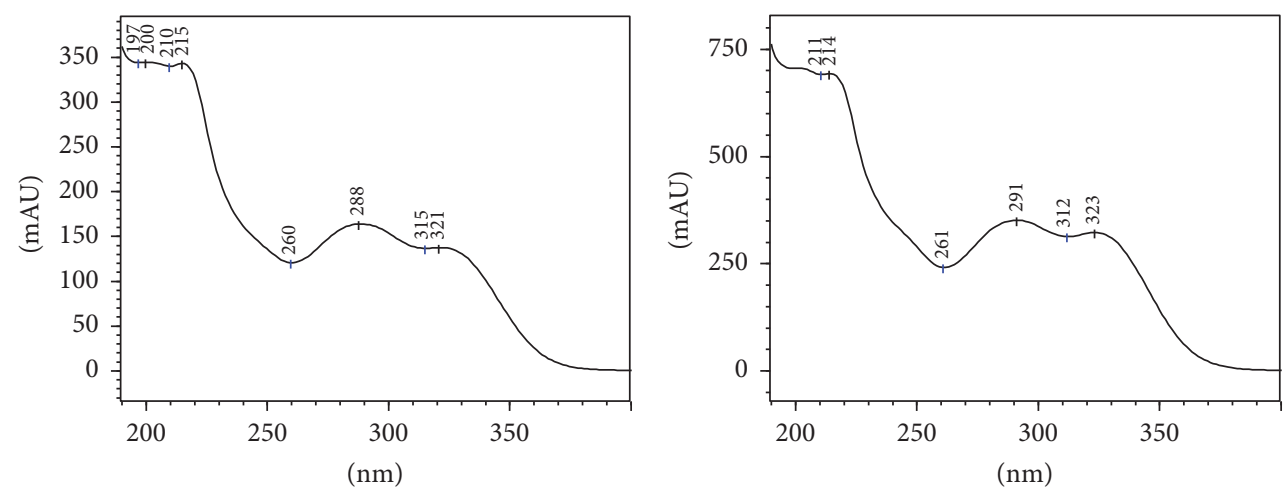

(c)

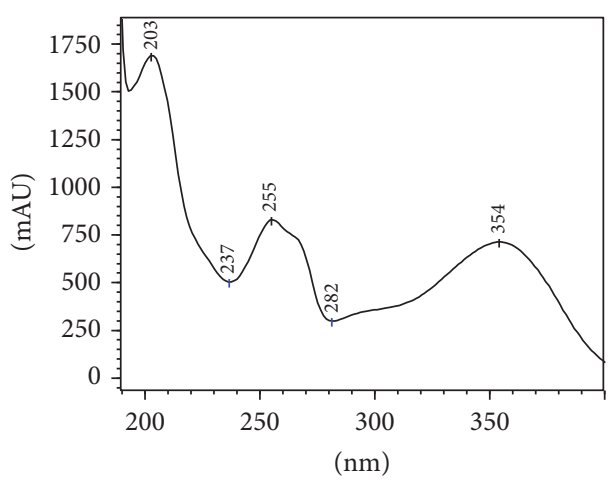

(d)

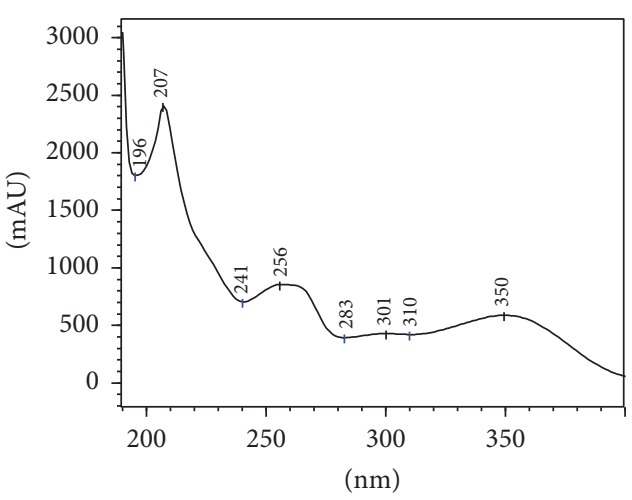

(e)

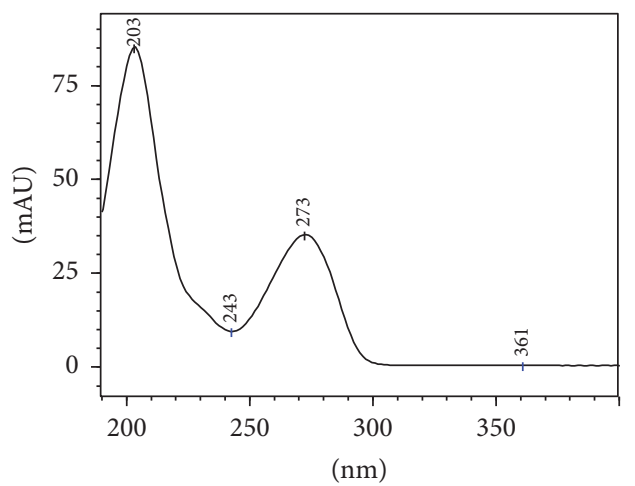

(g)

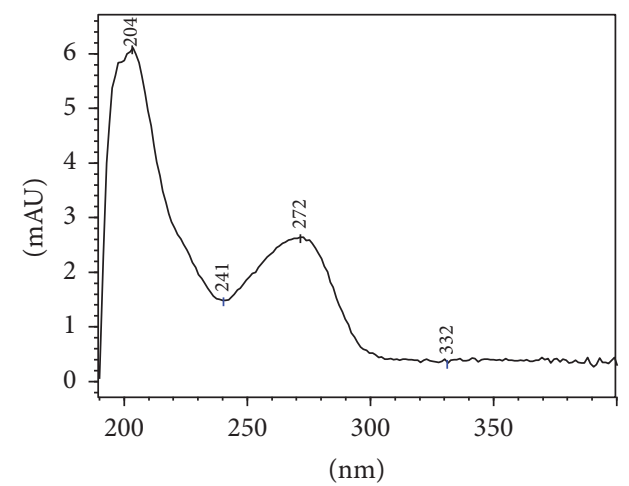

(h)

FIGURE 3: UV spectra obtained from DAD analysis applied to each chromatographic peak for standard references and C. xanthocarpa extract. (a) UV spectra for compound 1 (gallic acid) in standard reference; (b) UV spectra for compound 1 (gallic acid) in the extract; (c) UV spectra for compound 2 (chlorogenic acid) in standard reference; (d) UV spectra for compound 2 (chlorogenic acid) in the extract; (e) UV spectra for compound 3 (quercetin) in standard reference; (f) UV spectra for compound 3 (quercetin) in the extract; (g) UV spectra for compound 8 (theobromine) in standard reference; and (h) UV spectra for compound 8 (theobromine) in the extract. 


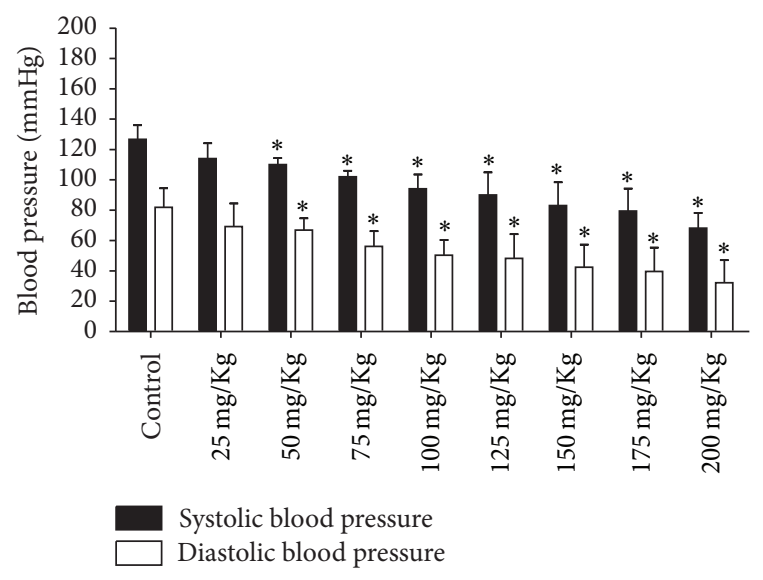

(a)

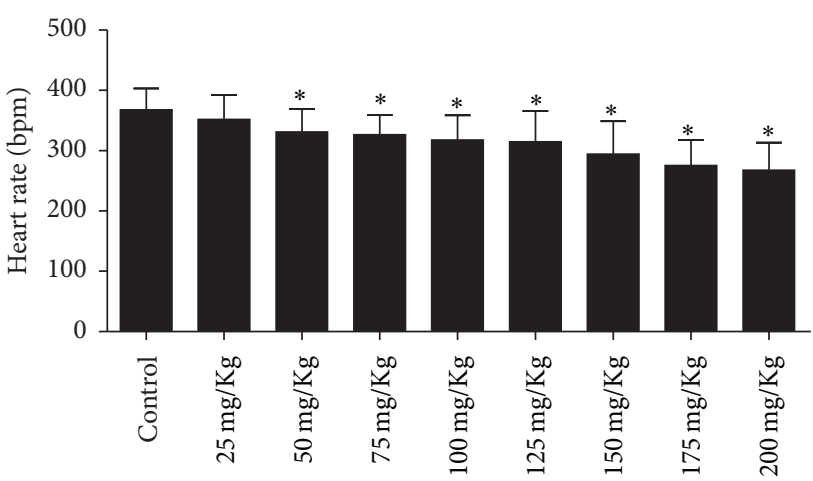

(b)

FIgURE 4: Evaluation of hemodynamic parameters in the dosage curve of $C$. xanthocarpa extract. (a) Register of the systolic and diastolic blood pressure with different administration of extract doses. (b) Heart rate during curve dosage of C. xanthocarpa extract. ${ }^{*} p<0.05$ versus control $(n=8)$.

interactions between the compound and AT1R are shown in Figure 7.

\section{Discussion}

Many phytochemical studies provide evidence of the presence of phenolic compounds and flavonoids in the Campomanesia genus [27, 28]. Some demonstrate higher values than the findings in our study, which can be justified by several factors, including seasonality, the type of soil in which the plant was grown, water availability, nutrient supply, minerals, development stage, temperature, ultraviolet radiation, induction by mechanical action stimuli, or pathogens [29].

Because phenolic compounds and flavonoids are known to have many pharmacological activities, the C. xanthocarpa extract may have promising biological effects. The phenolic compounds gallic acid, quercetin, and chlorogenic acid have several biologically related uses, such as analgesic, antidiabetic, anti-inflammatory, antiobesity, antioxidant, cardioprotective, hypotensive, and neuroprotective effects [30-33]. These substances, observed in our study, have already been shown in other studies with plants of the Myrtaceae family [34-36].

Phenolic compounds, mainly flavonoids, beyond other biological activities, act as antioxidants, not only for their ability to donate hydrogen or electrons but also because of their stable intermediate radical, which prevents the oxidation of several food molecules, particularly lipids [28]. The well-recognized antioxidant properties of flavonoids resulted in the interest in their potential role in prevention of cardiovascular diseases [37].

The antioxidant properties of natural products depend not only on polyphenol content but also on type. For instance, quercetin and catechin demonstrate the greatest antioxidant properties in vitro [38]. Studies have shown the effect of quercetin on the prevention and treatment of cardiovascular diseases, cancer, and renal and hepatic insufficiency [39]. These actions could be linked to the ability of the maintenance of vascular integrity due to the sequestration of free radicals and the inhibition of lipid peroxidation, lipoxygenase, cyclooxygenase, and phospholipase A2 activity. They also inhibit LDL oxidation, platelet aggregation, and $\mathrm{C}$ kinase protein activity and promote vasodilatation [31]. Thus, the high content of quercetin in C. xanthocarpa extract can be related to its hypotensive action.

Chlorogenic acid and gallic acid are present in the studied extract. These substances are phenolic compounds with important biological properties beyond antioxidant action; they also have insulin-sensitizing activities, reduce hyperglycemia via several mechanisms, and have a cardioprotective effect $[32,40]$.

Other secondary plant metabolites are alkaloids, the most diverse group found in living organisms with an array of structure types, biosynthetic pathways, and pharmacological activities [41]. The alkaloid theobromine (3,7-dimethylxanthine; 3,7-DMX) derived from caffeine metabolism has a moderate diuretic effect on the kidneys, causes mild cardiac stimulation, and acts on the central nervous system and cardiovascular, renal, and digestive systems [42, 43]. It also increases serum HDL-cholesterol concentrations that may be important in CVD prevention [44]. However, this is the first time that this compound is reported in C. xanthocarpa; its main existence is related to other species such as Paullinia cupana, Ilex paraguariensis, Coffea arabica, Theobroma cacao, and Camelia sinensis [45-48].

The dose nature of effects of the extract on blood pressure and heart rate of the rats suggests a cumulative action of the active substances present in the leaves of the plant. Thus, we can attribute the hypotensive effect of C. xanthocarpa to its phenolic and alkaloid compounds. Despite some reports, the present study is the first that describes the hypotensive activity of this extract, which is extremely important because the incidence of hypertension and use of medicinal plants have been increasing worldwide, generating future potential natural therapies. 

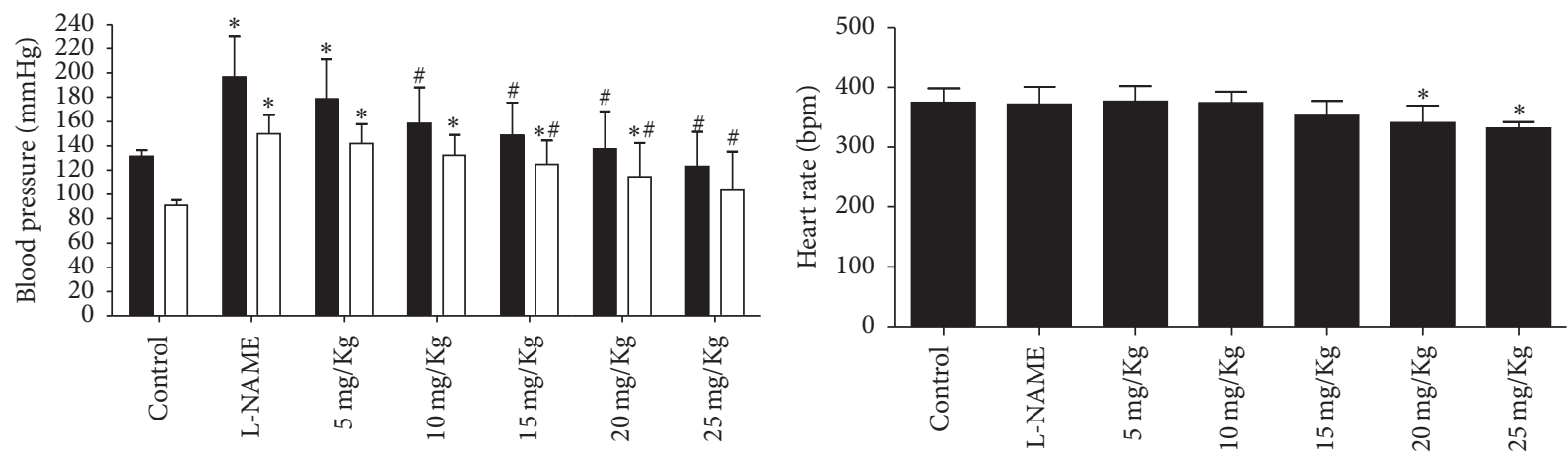

Systolic blood pressure Diastolic blood pressure

(a)

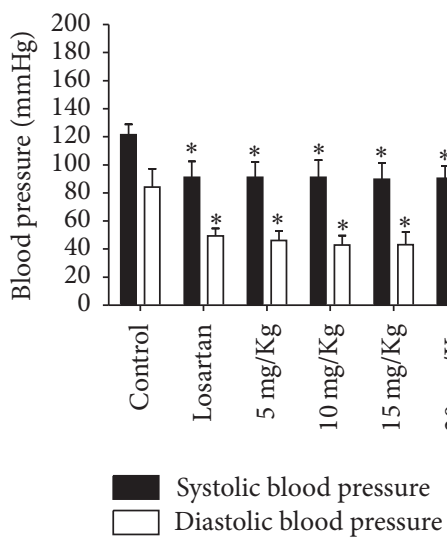

(c)

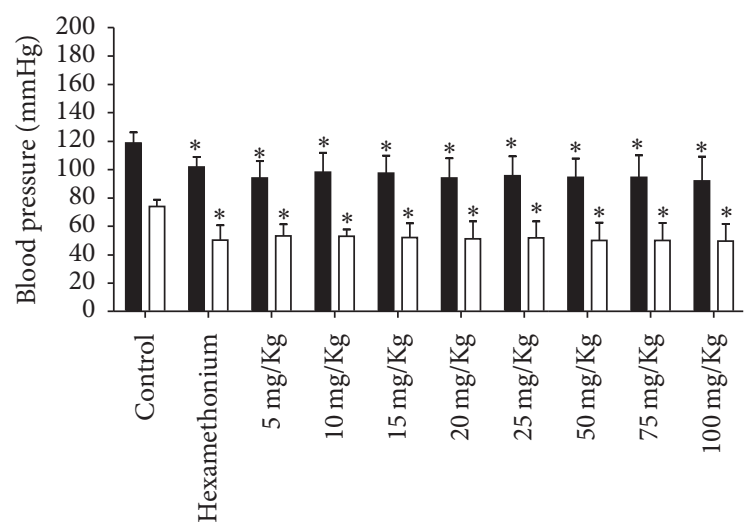

Systolic blood pressure

Diastolic blood pressure

(e) (b)

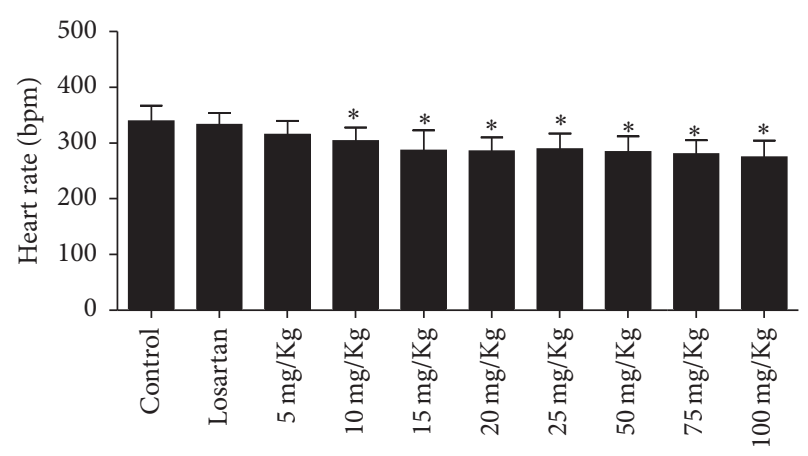

(d)

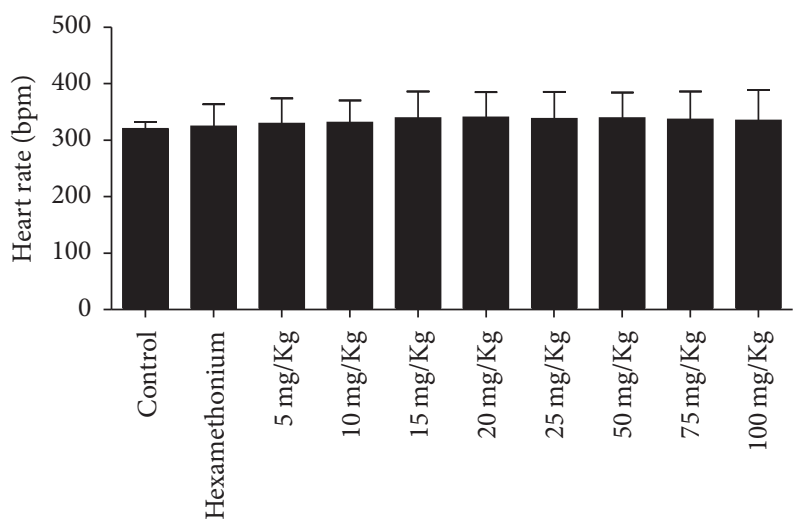

(f)

FIGURE 5: Evaluation of hemodynamic parameters in rats treated with C. xanthocarpa extract in the presence of different drug administration. (a) Register of the systolic and diastolic blood pressure with extract in the presence of L-NAME (30 mg/kg). (b) Register of heart rate during L-NAME protocol. (c) Register of the systolic and diastolic blood pressure with extract in the presence of losartan (20 mg/kg). (d) Register of heart rate during losartan protocol. (e) Register of the systolic and diastolic blood pressure with extract in the presence of hexamethonium $(10 \mathrm{mg} / \mathrm{kg})$. (f) Register of heart rate during hexamethonium protocol. ${ }^{*} p<0.05$ versus control and ${ }^{\#} p<0.05$ versus drug $(n=6)$. 


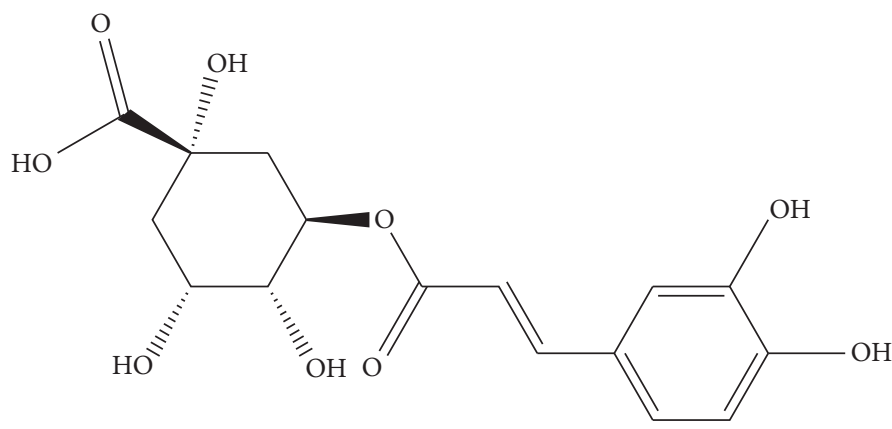

(a)<smiles>O=c1c(O)c(-c2ccc(O)c(O)c2)oc2cc(O)cc(O)c12</smiles>

(b)

Figure 6: Chemical structure of chlorogenic acid (a) and quercetin (b).

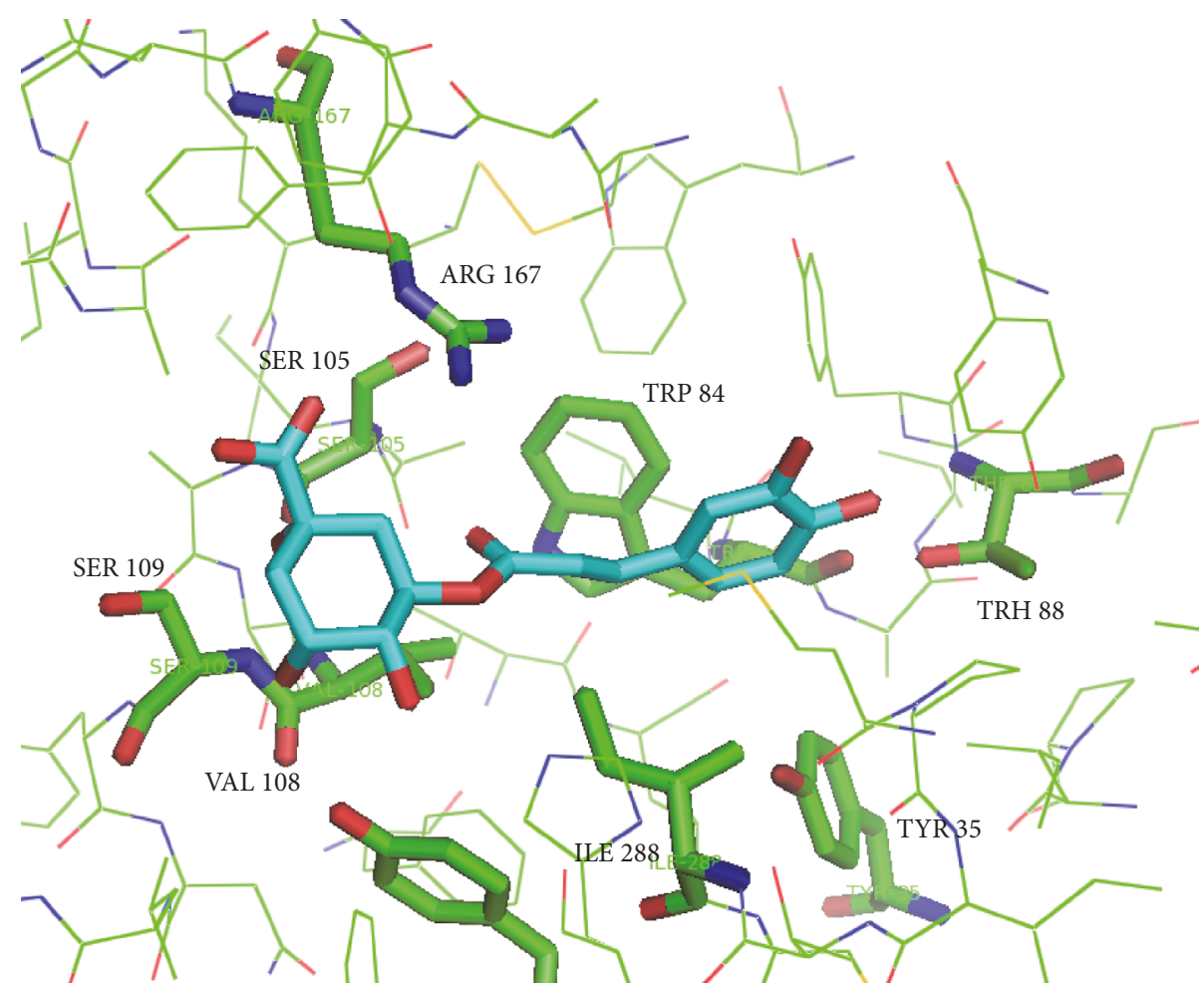

FIGURE 7: Binding of chlorogenic acid and quercetin in the active site of AT1R (PDB: 4YAY). Graphic visualization obtained using PyMOL (v.0.99).

To investigate the mechanism of the hypotensive action of C. xanthocarpa, drugs were administered before the extract. L-NAME is an analog of arginine competing for NO synthase and causes a hypertensive peak, resulting in the gross inhibition of NO synthesis [49]. It is widely used in experiments with rats as a model of systemic hypertension $[50,51]$. Thus, that the extract decreased blood pressure after administration of this drug suggests that NO synthase mechanism is not involved in the hypotensive effect.

Losartan acts through blocking the renin-angiotensin system by selectively antagonizing the receptors for angiotensin II, subtype AT1R. Previous evidence shows that the blockade of angiotensin AT1R results in reduced oxidative stress, inflammatory markers, and fibrinolysis inhibition [52].

Hexamethonium is potent and essentially devoid of neuromuscular blocking activity by a nicotinic receptor-blocking agent that blocks ion channels of the autonomic ganglia, resulting in blockage of the outputs of the sympathetic pathways $[53,54]$. Due to its charged structure, hexamethonium peripherally administered is presumed not to enter the brain and therefore is commonly used to distinguish peripheral ganglionic responses in vivo from those that arise centrally [53].

As the extract did not alter blood pressure after administration of losartan and hexamethonium, it can be suggested 
that the hypotensive action of the extract implicates the AT1R mechanism and sympathetic ganglionic blockade.

The docking procedure was aimed to identify individual poses of chlorogenic acid and quercetin, components of $C$. xanthocarpa extract, that may bind to the ATIR active site. Chlorogenic acid was chosen for the docking analysis for its recognized antihypertensive activity [33], and quercetin was selected because this compound showed downregulation of the ATIR in the kidneys [55].

The empirical scoring function of iGemDOCK is the estimated sum total of Van der Waals, H-bond, and electrostatic energy. In this case, the comparison of chlorogenic acid ligand poses chlorogenic acid and quercetin structures revealed similar conformations and conserved molecular recognition modes for antagonists and inverse agonists toward ATIR [24]. Chlorogenic acid and quercetin showed an affinity energy of -91.44 and $88.15 \mathrm{Kcal} \mathrm{mol}^{-1}$. Chlorogenic acid showed Van der Waals, $\mathrm{H}$-bond, and electrostatic interaction values of $-76.11,-13.35$, and $-1.98 \mathrm{Kcal} \mathrm{mol}^{-1}$, respectively, and quercetin showed only Van der Walls and H-bond at -62.01 and $26.14 \mathrm{Kcal} \mathrm{mol}^{-1}$, respectively. No electrostatic interaction of quercetin and ATIR was observed.

According to the data of docking experiments, main interactions occur with the residues TYR 35, TRP 84, THR 88, SER 105, VAL 108, SER 109, ARG 167, and ILE 288 (Figure 7). After the postscreening analysis using residue consensus analysis, ARG 167 was detected as the main residue involved in this ligand-receptor binding (with a $Z$-score of -1.12 and WPharma of 1.00) to chlorogenic acid only. The ARG 167 and TRP 84 residues are the same observed in the docking study Zhang et al. [24] performed, suggesting the active site of AT1R studied.

A model generated from chlorogenic acid suggests the interaction of H-bond, Van der Waals, and electrostatic types with ARG 167. The carboxylic acid attached to the cyclohexane ring of chlorogenic acid's chemical structure was located in the same spatial region as determined by the docking of the same moiety from the telmisartan or tetrazole ring from losartan [24]. The main type of interaction was a Van der Waals interaction with the TYR 35, TRP 84, SER 105, VAL 108, ARG 167, and ILE 288 residues. In the case of chlorogenic acid, there is a molecular distance of $2.82 \AA$ between ARG 167 and a carboxylic acid moiety attached to the hexane ring and the $2.82 \AA$ of hydrogen from hydroxyl group with THR 88, and $3.01 \AA$ of hydroxyl and SER 109 of AT1R were observed.

Some main interactions of the quercetin ligand and AT1R were H-bonds with ARG 167 and Van der Waals with the THR 84 and ILE 288 residues. Quercetin showed an interaction with the hydroxyl moiety attached to aromatic ring TYR 35; this group has distances of 2.8 and $3.10 \AA$ between hydroxyl groups and the flavonol nucleus. Carbonyl moiety from flavonols showed a molecular distance of $2.70 \AA$ of the nitrogen atom from the tetrazole ring of ARG 167. These data suggest that chlorogenic acid and quercetin, which are important components in the plant extract, may be the compounds causing the interaction of cardiac AT1R.
Based on these results, it can be concluded that the aqueous extract of $C$. xanthocarpa presents expressive phenolic and flavonoid content. Additionally, the presence of chlorogenic and gallic acid, quercetin, and theobromine in the extract was determined. It was hypothesized that two constituents of the plant may be attributed to its AT1R interaction. These substances already have a clinical potential described that can assist in the investigation of the pharmacological properties of this plant. However, the acute administration of the aqueous extract of $C$. xanthocarpa has a dose-dependent hypotensive effect in normotensive rats, and we suggest that this action may be mediated through the renin-angiotensin system by AT1R blockade and a sympathetic autonomic response.

\section{Conflicts of Interest}

The authors declare that there are no conflicts of interest regarding the publication of this paper.

\section{References}

[1] D. T. Dinh, A. G. Frauman, C. I. Johnston, and M. E. Fabiani, "Angiotensin receptors: distribution, signalling and function," Clinical Science (London), vol. 100, no. 5, pp. 481-492, 2001.

[2] L. P. Audoly, M. I. Oliverio, and T. M. Coffman, "Insights into the functions of type 1 (AT1) angiotensin II receptors provided by gene targeting," Trends in Endocrinology and Metabolism, vol. 11, no. 7, pp. 263-269, 2000.

[3] W. G. Thomas and F. A. O. Mendelsohn, "Angiotensin receptors: form and function and distribution," International Journal of Biochemistry and Cell Biology, vol. 35, no. 6, pp. 774-779, 2003.

[4] M. A. Zaman, S. Oparil, and D. A. Calhoun, "Drugs targeting the renin-angiotensin-aldosterone system," Nature Reviews Drug Discovery, vol. 1, no. 8, pp. 621-636, 2002.

[5] S. S. Karnik, H. Unal, J. R. Kemp et al., "International union of basic and clinical pharmacology. XCIX. angiotensin receptors: interpreters of pathophysiological angiotensinergic stimulis," Pharmacological Reviews, vol. 67, no. 4, pp. 754-819, 2015.

[6] S. Billet, F. Aguilar, C. Baudry, and E. Clauser, "Role of angiotensin II AT1 receptor activation in cardiovascular diseases," Kidney International, vol. 74, no. 11, pp. 1379-1384, 2008.

[7] M. C. Michel, C. Foster, H. R. Brunner, and L. Liu, "A systematic comparison of the properties of clinically used angiotensin II type 1 receptor antagonists," Pharmacological Reviews, vol. 65, no. 2, pp. 809-848, 2013.

[8] M. S. Akhtar, Q. Alamgeer, H. U. Jabeen et al., "Pharmacological evaluation of antihypertensive effect of aerial parts of thymus linearis benth," Acta Poloniae Pharmaceutica-Drug Research, vol. 71, no. 4, pp. 677-682, 2014.

[9] C. B. Alice, N. C. S. Siqueira, L. A. Mentz, G. A. A. Brasil, and K. F. D. José Silva, "Plantas medicinais de uso popular" Atlas Farmacognóstico, Ulbra, Canoas, Brazil, 1995.

[10] M. L. Dickel, S. M. K. Rates, and M. R. Ritter, "Plants popularly used for loosing weight purposes in Porto Alegre, South Brazil," Journal of Ethnopharmacology, vol. 109, no. 1, pp. 60-71, 2007.

[11] J. B. F. Fernandes and V. M. F. Vargas, "Mutagenic and antimutagenic potential of the medicinal plants $M$. laevigata and $C$. xanthocarpa," Phytotherapy Research, vol. 17, no. 3, pp. 269-273, 2003. 
[12] T. Pastori, F. C. Flores, A. A. Boligon et al., "Genotoxic effects of Campomanesia xanthocarpa extracts on Allium cepa vegetal system," Pharmaceutical Biology, vol. 51, no. 10, pp. 1249-1255, 2013.

[13] J. Z. Klafke, A. M. Da Silva, M. F. Rossato et al., "Antiplatelet, antithrombotic, and fibrinolytic activities of Campomanesia xanthocarpa," Evidence-Based Complementary and Alternative Medicine, vol. 2012, Article ID 954748, 8 pages, 2012.

[14] J. Z. Klafke, M. A. da Silva, T. F. Panigas et al., "Effects of Campomanesia xanthocarpa on biochemical, hematological and oxidative stress parameters in hypercholesterolemic patients," Journal of Ethnopharmacology, vol. 127, no. 2, pp. 299-305, 2010.

[15] B. E. O. Markman, E. M. Bacchi, and E. T. M. Kato, "Antiulcerogenic effects of Campomanesia xanthocarpa," Journal of Ethnopharmacology, vol. 94, no. 1, pp. 55-57, 2004.

[16] P. R. N. Viecili, D. O. Borges, K. Kirsten et al., "Effects of Campomanesia xanthocarpa on inflammatory processes, oxidative stress, endothelial dysfunction and lipid biomarkers in hypercholesterolemic individuals," Atherosclerosis, vol. 234, no. 1, pp. 85-92, 2014.

[17] J. Z. Klafke, R. L. D. Pereira, G. E. Hirsch et al., "Study of oxidative and inflammatory parameters in LDLr-KO mice treated with a hypercholesterolemic diet: Comparison between the use of Campomanesia xanthocarpa and acetylsalicylic acid," Phytomedicine, vol. 23, no. 11, pp. 1227-1234, 2016.

[18] S. Sahreen, M. R. Khan, R. A. Khan, and T. B. Hadda, "Evaluation of phytochemical content, antimicrobial, cytotoxic and antitumor activities of extract from Rumex hastatus D. Don roots," BMC Complementary and Alternative Medicine, vol. 15, no. 1, article 211, 2015.

[19] C. Chang, M. Yang, H. Wen, and J. Chern, "Estimation of total flavonoid content in propolis by two complementary colorimetric methods," Journal of Food and Drug Analysis, vol. 10, no. 3, pp. 178-182, 2002.

[20] X. R. Yang, C. X. Ye, J. K. Xu, and Y. M. Jiang, "Simultaneous analysis of purine alkaloids and catechins in Camellia sinensis, Camellia ptilophylla and Camellia assamica var. kucha by HPLC," Food Chemistry, vol. 100, no. 3, pp. 1132-1136, 2007.

[21] M. Chaswal, S. Das, J. Prasad, A. Katyal, and M. Fahim, "Cardiac autonomic function in acutely nitric oxide deficient hypertensive rats: role of the sympathetic nervous system and oxidative stress," Canadian Journal of Physiology and Pharmacology, vol. 24, pp. 865-874, 2011.

[22] V. C. Biancardi, C. T. Bergamaschi, O. U. Lopes, and R. R. Campos, "Sympathetic activation in rats with L-NAMEinduced hypertension," Brazilian Journal of Medical and Biological Research, vol. 40, no. 3, pp. 401-408, 2007.

[23] J. P. Collister, B. J. Hornfeldt, and J. W. Osborn, "Hypotensive response to Losartan in normal rats: role of Ang II and the area postrema," Hypertension, vol. 27, no. 3, pp. 598-606, 1996.

[24] H. Zhang, H. Unal, C. Gati et al., "Structure of the angiotensin receptor revealed by serial femtosecond crystallography," Cell, vol. 161, pp. 833-844, 2015.

[25] G. M. Morris, H. Ruth, W. Lindstrom et al., "AutoDock4 and AutoDockTools4: automated docking with selective receptor flexibility," Journal of Computational Chemistry, vol. 30, no. 16, pp. 2785-2791, 2009.

[26] J. M. Yang and C. C. Chen, "GEMDOCK: a generic evolutionary method for molecular docking," Proteins: Structure, Function and Genetics, vol. 55, no. 2, pp. 288-304, 2004.
[27] V. M. F. Kataoka and C. A. L. Cardoso, "Avaliação do perfil cromatográfico obtidos por CLAE-DAD e da atividade antioxidante das folhas de espécies Campomanesia sessiliflora $\mathrm{O}$. Berg Mattos e Campomanesia xanthocarpa O. Berg," Revista Brasileira de Plantas Medicinais, vol. 15, no. 1, pp. 121-129, 2013.

[28] M. L. Silva, R. S. Costa, A. D. Santana, and M. G. B. Koblitz, "Compostos fenólicos, carotenóides e atividade antioxidante em produtos vegetais," Semina: Ciências Agrárias, vol. 31, no. 3, p. 669, 2010.

[29] L. Gobbo-Neto and N. P. Lopes, "Plantas medicinais: fatores de influência no conteúdo de metabólitos secundários," Revista Química Nova, vol. 30, no. 2, pp. 374-381, 2007.

[30] M. D. dos Santos, M. C. Almeida, N. P. Lopes, and G. E. P. de Souza, "Evaluation of the anti-inflammatory, analgesic and antipyretic activities of the natural polyphenol chlorogenic acid," Biological and Pharmaceutical Bulletin, vol. 29, no. 11, pp. 22362240, 2006.

[31] J. V. Formica and W. Regelson, "Review of the biology of quercetin and related bioflavonoids," Food and Chemical Toxicology, vol. 33, no. 12, pp. 1061-1080, 1995.

[32] S. S. Patel and R. K. Goyal, "Cardioprotective effects of gallic acid in diabetes-induced myocardial dysfunction in rats," Pharmacognosy Research, vol. 3, no. 4, pp. 239-245, 2011.

[33] Y. Zhao, J. Wang, O. Ballevre, H. Luo, and W. Zhang, "Antihypertensive effects and mechanisms of chlorogenic acids," Hypertension Research, vol. 35, no. 4, pp. 370-374, 2012.

[34] I. I. Mahmoud, M. S. A. Marzouk, F. A. Moharram, M. R. ElGindi, and A. M. K. Hassan, "Acylated flavonol glycosides from eugenia jambolana leaves," Phytochemistry, vol. 58, no. 8, pp. 1239-1244, 2001.

[35] G. Schmeda-Hirschmann, "Flavonoids from calycorectes, campomanesia, eugenia and hexachlamys species," Fitoterapia, vol. 66, no. 4, pp. 373-374, 1995.

[36] L. Zhang and B. L. Lokeshwar, "Medicinal properties of the Jamaican pepper plant pimenta dioica and allspice," Current Drug Targets, vol. 13, no. 14, pp. 1900-1906, 2012.

[37] M. Majewska-Wierzbicka and H. Czeczot, "Flavonoids in the prevention and treatment of cardiovascular diseases," Polski Merkuriusz Lekarski, vol. 32, pp. 50-54, 2012.

[38] H. Czeczot and M. Podsiad, "Antioxidant status of quercetin," Bromatologia i Chemia Toksykologiczna, vol. 38, no. 4, pp. 329334, 2005.

[39] E. B. Behling, M. C. Sendão, H. D. C. Francescato, L. M. G. Antunes, and M. L. P. Bianchi, "Flavonóide quercetina: aspectos gerais e ações biológicas," Alimentos e Nutrição Araraquara, vol. 15, no. 3, pp. 285-292, 2004.

[40] N. Stefanello, R. Schmatz, L. B. Pereira et al., "Effects of chlorogenic acid, caffeine and coffee on components of the purinergic system of STZ-induced diabetic rats," The Journal of Nutritional Biochemistry, 2016.

[41] M. F. Roberts and M. Wink, Alkaloids: Biochemistry, Ecology and Medicinal Applications, Plenum Press, 1998.

[42] M. Bonati, R. Latini, B. Sadurska et al., "Kinetics and metabolism of theobromine in male rats," Toxicology, vol. 30, no. 4, pp. 327-341, 1984.

[43] J. Sawynok, "Pharmacological rationale for the clinical use of caffeine," Drugs, vol. 49, no. 1, pp. 37-50, 1995.

[44] J. F. M. Cruz, P. B. Leite, S. E. Soares, and E. D. S. Bispo, "Bioactive compounds in different cocoa (Theobroma cacao, L) cultivars during fermentation," Food Science and Technology, vol. 35 , no. 2, pp. 279-284, 2015. 
[45] G. Caprioli, D. Fiorini, F. Maggi et al., "Nutritional composition, bioactive compounds and volatile profile of cocoa beans from different regions of Cameroon," International Journal of Food Sciences and Nutrition, vol. 67, no. 4, pp. 422-430, 2016.

[46] S. C. Gnoatto, V. L. Bassani, G. C. Coelho, and E. P. Schenkel, "Influência do método de extração nos teores de metilxantinas em erva-mate (Ilex paraguariensis a. St.-Hil., aquifoliaceae)," Revista Química Nova, vol. 30, no. 2, pp. 304-307, 2007.

[47] P. A. N. Punyasiri, B. Jeganathan, J. D. Kottawa-Arachchi et al., "New sample preparation method for quantification of phenolic compounds of tea (Camellia sinensis L. Kuntze): a polyphenol rich plant," Journal of Analytical Methods in Chemistry, vol. 2015, Article ID 964341, 6 pages, 2015.

[48] S. A. Sousa, S. F. Alves, J. A. M. Paula, T. S. Fiuza, J. R. Paula, and M. T. F. Bara, "Determinação de taninos e metilxantinas no guaraná em pó (Paullinia cupana Kunth, Sapindaceae) por cromatografia líquida de alta eficiência," Revista Brasileira de Farmacognosia, vol. 20, no. 6, pp. 866-870, 2010.

[49] J. Kopincová, A. Púzserová, and I. Bernátová, "L-NAME in the cardiovascular system - nitric oxide synthase activator?” Pharmacological Reports, vol. 64, no. 3, pp. 511-520, 2012.

[50] D. G. Kang, E. J. Sohn, Y. M. Lee et al., "Effects of bulbus Fritillaria water extract on blood pressure and renal functions in the L-NAME-induced hypertensive rats," Journal of Ethnopharmacology, vol. 91, no. 1, pp. 51-56, 2004.

[51] M. Saravanakumar and B. Raja, "Veratric acid, a phenolic acid attenuates blood pressure and oxidative stress in L-NAME induced hypertensive rats," European Journal of Pharmacology, vol. 671, no. 1-3, pp. 87-94, 2011.

[52] G. Czechowska, K. Celinski, A. Korolczuk et al., "The effect of the angiotensin II receptor, type 1 receptor antagonists, losartan and telmisartan, on thioacetamide-induced liver fibrosis in rats," Journal of Physiology and Pharmacology, vol. 67, no. 4, pp. 575-586, 2016.

[53] M. W. Holladay, J. D. Michael, and K. L. John, "Neuronal nicotinic acetylcholine receptors as targets for drug discovery," Journal of Medicinal Chemistry, vol. 40, no. 26, pp. 4169-4194, 1997.

[54] A. Ismail, M. Mohamed, S. A. Sulaiman, and W. A. N. Wan Ahmad, "Autonomic nervous system mediates the hypotensive effects of aqueous and residual methanolic extracts of Syzygium polyanthum (Wight) Walp. var. polyanthum leaves in anaesthetized rats," Evidence-Based Complementary and Alternative Medicine, vol. 2013, Article ID 716532, 16 pages, 2013.

[55] I. Mackraj, T. Govender, and S. Ramesar, "The antihypertensive effects of quercetin in a salt-sensitive model of hypertension," Journal of Cardiovascular Pharmacology, vol. 51, no. 3, pp. 239245, 2008. 


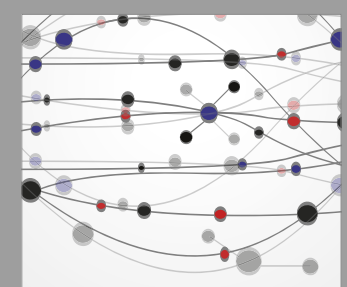

The Scientific World Journal
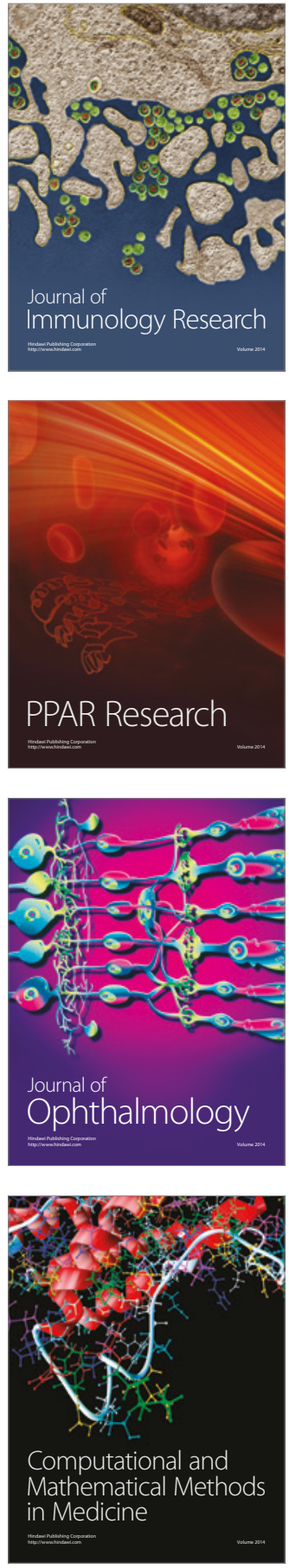

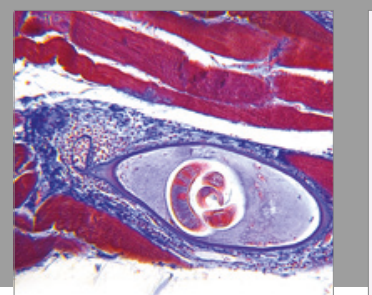

Gastroenterology Research and Practice
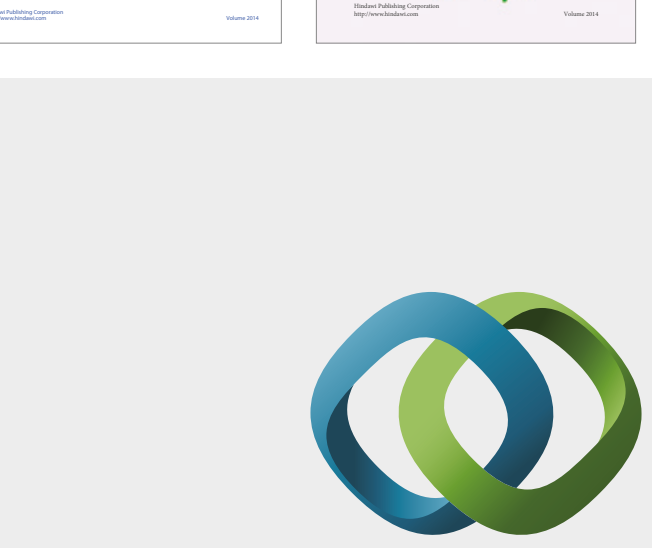

\section{Hindawi}

Submit your manuscripts at

https://www.hindawi.com
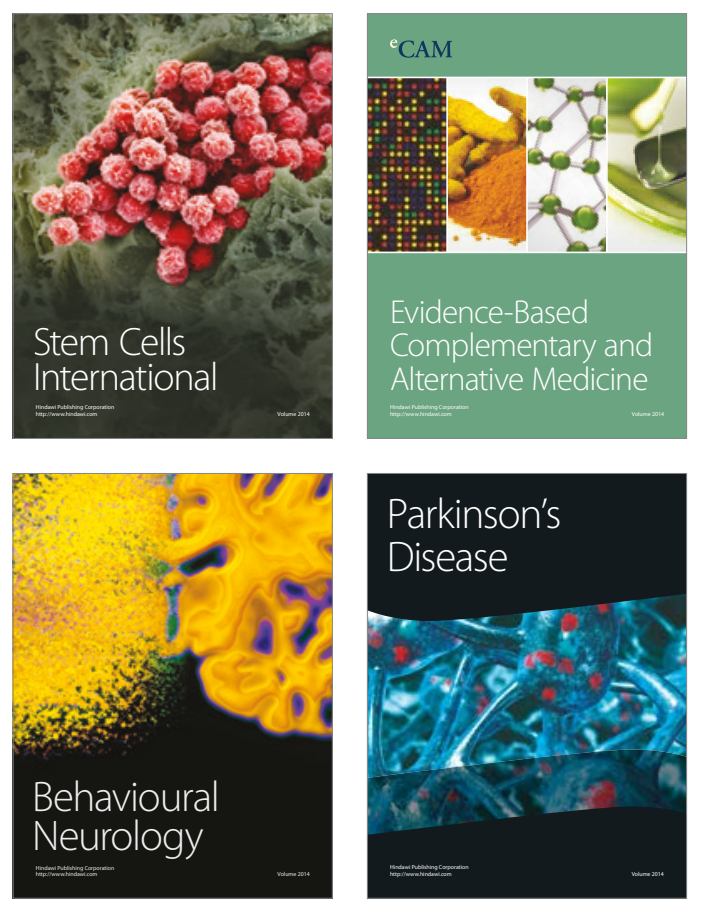
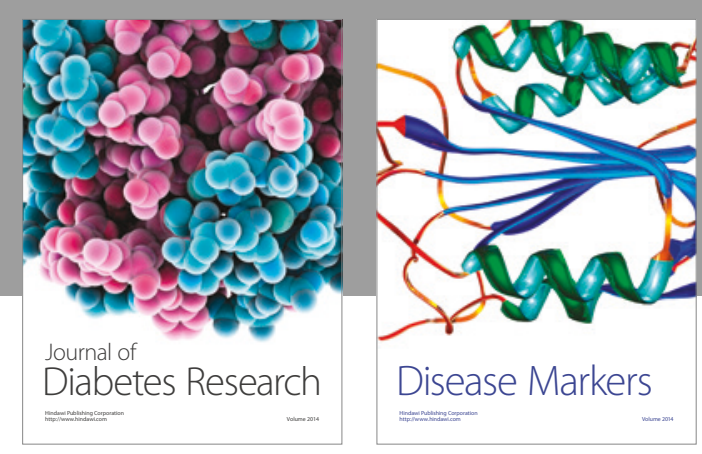

Disease Markers
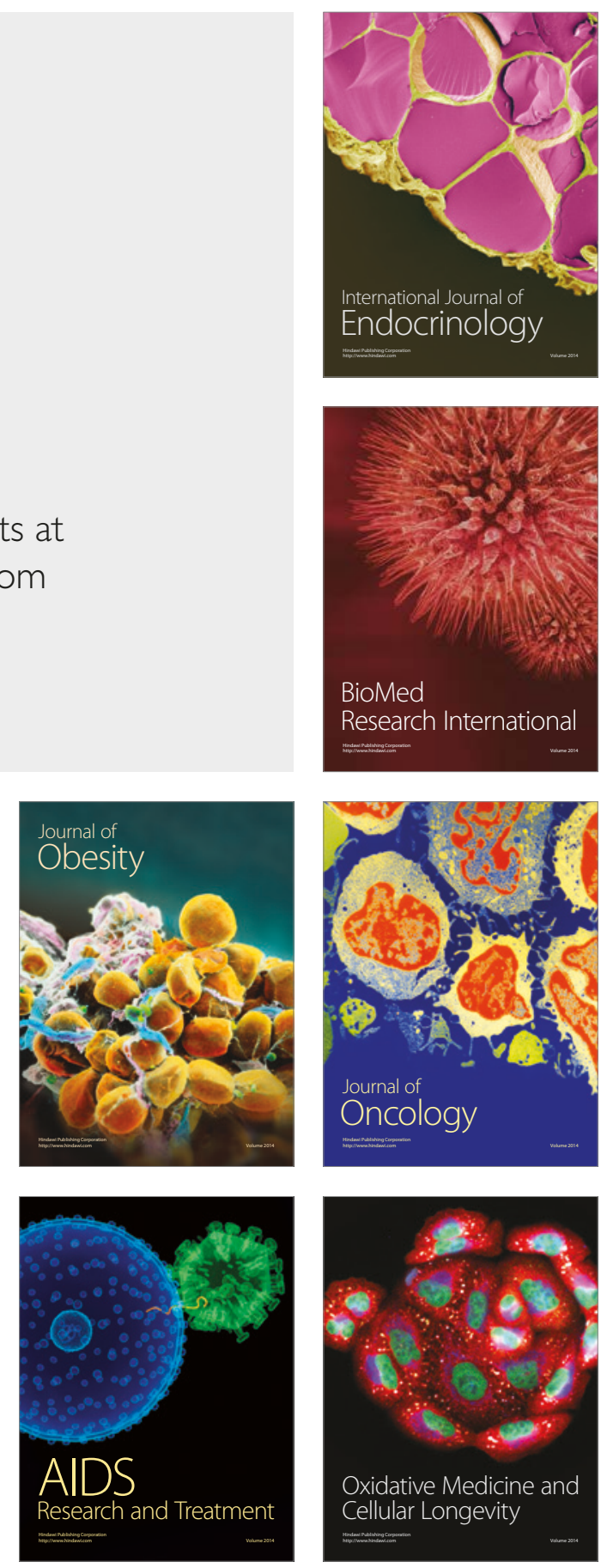